\title{
Letter: The unbearable lightness of the evaluation of research projects: do we need to regularize the professional activity of research evaluation?
}

\author{
Enrique Orduña-Malea
}

Nota: Este artículo se puede leer en español en:

http://www.profesionaldelainformacion.com/contenidos/2021/sep/orduna_es.pdf

How to cite this article:

Orduña-Malea, Enrique (2021). "The unbearable lightness of the evaluation of research projects: do we need to regularize the professional activity of research evaluation?". Profesional de la información, v. 30, n. 5, e300413.

https://doi.org/10.3145/epi.2021.sep.13

Letter received on August, $23^{\text {rd }} 2021$

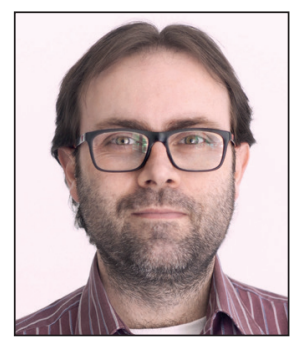

\author{
Enrique Orduña-Malea \\ https://orcid.org/0000-0002-1989-8477 \\ Universitat Politècnica de València \\ Department of Audiovisual Communication, \\ Documentation and History of Art \\ Camí de Vera, s/n. Edifici $1 \mathrm{H}$ \\ 46022 Valencia, Spain \\ enorma@upv.es
}

\begin{abstract}
This letter aims to highlight severe inconsistencies in the scientific evaluation of regionally publicly funded research projects, uncovering structural failures related to the public management of science that go beyond technical aspects of bibliometrics. This problem is exemplified through an illustrative case study (the public grants program to emerging research groups funded by the regional government of the Valencian region, Spain, NUTS-2), describing three complementary aspects of this call (the evaluation system, the evaluation process, and the communication of the evaluation). The problems illustrated by this case study lead to a general problem related to the nonstrategic use of science. Finally, the national and international regularization of the professional activity of research evaluation in general, and bibliometrics in particular, is proposed as a route to avoid mismanagement of science (and scientific evaluation).
\end{abstract}

\section{Keywords}

Research evaluation; Bibliometrics; Research projects; Public funding of science; Science of science; Metaresearch; Regional research calls; Science management.

\section{Dear Editor,}

A recent letter co-authored by Delgado-López-Cózar, Ràfols, and Abadal (2021), and subsequently replied to by Aguillo (2021) and Codina (2021), raised concerns related to the evaluation of research in Spain.

Principally, although not exclusively, the concerns systematized and discussed in those letters centered on the evaluation of individuals (researchers) through the work they carry out and the impact (echo) of their results and findings. Such evaluations are generally required to achieve accreditation (which enables university teaching staff to access different scales, i.e., to be promoted) or to achieve a positive research period (which leads to an economic reward as well as certain privileges within the university, i.e., prestige).

Although the evaluation of individuals is of the utmost importance (affecting not only research careers but also personal lives), the evaluation of science is complex, involving a wide range of agents and aspects, among which the evaluation of research projects stands out. 


\section{The preamble: research projects}

The importance of public funding of research projects is beyond doubt, since researchers cannot accomplish their tasks solely with the human and economic resources provided by their institutions (especially in the empirical disciplines).

Research projects can range from complex international calls with large budgets and involving groups from different countries and fields of knowledge, to simple regional or even institutional calls involving a few researchers managing limited funding.

In particular, regional public calls are critical for emerging groups with incipient curricula as well as consolidated groups with locally focused lines of research and thus fewer opportunities to tender successfully for more competitive calls.

As funding for science is limited, competitive calls may include a research evaluation process, usually focused on either the specific research proposal (i.e., measuring and valuing the interest in and necessity for the topic and the quality of the project design) or the team's CVs (i.e., measurement and valuation of the researchers' careers to date). Generally, such evaluations may also include a mixture of both types.

The evaluation of research projects, especially of the members of the research groups, inherits most of the problems and deficiencies mentioned in the cited letters, in addition to other problems of a structural and systemic nature, representing the main topic of the current letter.

Unfortunately, while general and specialized media generally echo the most elitist calls endowed with the largest budgets (the evaluative aspects of which are generally more carefully controlled), the irregularities found in regionally publicly funding calls remain unnoticed, even by international science of science and research evaluation experts.

The identification and detailed description of such irregularities in the evaluation of research projects in regional calls should be highlighted to raise awareness of the magnitude of the failures and faults existing in research evaluation, which remain hidden in letters making wider claims, whose scope and structure does not allow particular case studies to be considered. Highlighting particular cases at the regional level is the specific aim of the current letter.

\section{The case study: emerging groups}

The 2021 public grants program to emerging research groups funded by the regional government of the Valencian region (Spain, NUTS-2) is used in this letter as an illustrative case study. This program is part of the Subsidies of the Program for the Promotion of Scientific Research, Technological Development, and Innovation in the Valencian community (I+D+I Program). https://innova.gva.es/es/web/ciencia/a-programa-i-d-i1/-/asset_publisher/jMe1UDRYZMHO/content/ix-subvencionesa-grupos-de-investigacion-emergentes

Three complementary aspects of this call (the evaluation system, the evaluation process, and the communication of the evaluation) are described below.

\section{a) The evaluation system}

The final score relies basically on the coherence of the group's composition (20\%) and the curricula of the team members (80\%). The principal investigator's curriculum accounts for $50 \%$ of the overall final score, whereas the scientific careers of the other team members account for $30 \%$. The evaluation of the CVs is based on scientific production, participation in international research groups, presentations at international congresses, supervisions of master theses and doctoral dissertations, research contracts or projects of special relevance, and patents.

A research proposal is requested but is neither evaluated nor considered in the final score. Perhaps for this reason, there are no specific guidelines to complement such proposals. The sections that the proposal should include are not even indicated. The proposal template uses inclusive language incorrectly and also includes various spelling mistakes.

This call employs a nontransparent evaluation system. There is no public information about how the merits will be evaluated, as no evaluation criteria are made available. The official documentation just mentions "scientific production." Nevertheless, applicants do not know whether the criterion applied will be quantitative (number of publications), selective (number of publications in certain journals or sources), or impact based (for example, number of citations received). It is also not possible to check whether proper research evaluation practices are applied.

The adequacy of the evaluation regarding the differences existing between research disciplines is also unknown. The call admits proposals from up to 18 different fields, ${ }^{1}$ all of which exhibit significant differences in scientific production (and impact) that must be considered. Again, it is not possible to confirm whether proper research evaluation practices are applied.
It is disheartening to see how regional public governments manage science with such disinterest, inefficiency, and lack of professionalism, while demanding the maximum from researchers 
The absence of ex ante evaluation rubrics (before the evaluation) is not recommended practice, since post facto rubrics (if any) cannot guarantee the transparency of the process as they could have been adapted to fit the decisions made, limiting the possibility of appeal; That is, the rules of the game should not be communicated to the applicants when the results have already been announced. In this particular case, the rules have not even been communicated yet.

Finally, applicants can obtain an extra score (5\% of the total score obtained) if the principal investigator is a woman. The official call includes an illustrative table (Annex XV) presenting the gender imbalance by thematic area (the percentage of men and women for each area and the gender bias) to evidence the necessity for this gender-based policy. However, the gender bias exhibits a wide statistical range (from 1.50 in biomedicine to 36.20 in energy and transport). Therefore, the fixed extra score of $5 \%$ for all applications regardless of their field of research seems quite inaccurate, prejudicing women in areas with a more pronounced gender bias, for example.

\section{b) The evaluation process}

The evaluation process is unjustifiable slow. It took 125 days from the deadline for the 2020 call to start the external review process, and 220 days to publish the resolution, which included 187 applications.

The slowness of the evaluation process makes the management of the grants received economically inefficient. The 2020 call solicited that all projects be carried out from 1 January 2021 onwards, admitting projects lasting 12 or 24 months. Given that the announcement of the final resolution is still awaited in September 2021, projects will start with a delay of at least 8 months. Those aiming to finish by December 2021 will have less than four months to complete the project, and to justify expenses. This will mean a change in the execution of the project in the best of cases, and an inability to carry them out in the worst. The pandemic does not represent a justification, since this circumstance has occurred on numerous occasions with previous calls, thus representing a systematic and endemic problem.

Unfortunately, this does not only happen in calls for emerging groups as illustrated in this letter; it also occurs in calls for consolidated groups or for the organization and advertising of international congresses, whose applicants still do not know as of August 2021 whether they will be beneficiaries of grants for events that will be held before year end.

The lack of transparency should also be commented on, since no data regarding the composition of the pool of external reviewers (e.g., the number of reviewers per discipline and gender, their academic degrees or affiliations) is made public. Indeed, since the evaluation of the proposals is mainly based on the researchers' careers (considering the merit of their CVs), the need for external evaluators by field should be discussed, especially if the only task they are going to carry out is counting the number of items in each curriculum. In the specific case of the evaluation of applicants' scientific production, it would be appropriate to know whether the pool of external evaluators has training in bibliometrics, especially if bibliometric indicators are to be used in the evaluation (another aspect that remains unknown).

\section{c) The communication of the evaluation}

This call also exhibits professional malpractice in the official communication of the results. The 2020 call was provisionally resolved (although still without legal validity) on Friday 30 July at around 15:00, precisely at the time when public workers and university applicants officially began their summer holidays in Spain (with August not counting for administrative processes). Therefore, appeals are not allowed until September 2021. Moreover, applicants were not officially notified about this provisional resolution.

https://innova.gva.es/documents/161863198/172397122/RESOLUCI\%C3\%93\%20CONVOCATORIA+ajudes+per+a+2021 /1a493e0b-1b72-43cb-8e60-e4b97d754af4

Last but not least, no review report was delivered to the applicants to justify the score obtained (a practice employed in the evaluation of other research projects). The possibility of requesting it on demand has not even been given yet.

With this letter, I aim to highlight the helplessness felt by researchers in the face of such black-box evaluation processes carried out in regional settings, beyond the media spotlight, where nontransparent criteria are used and inefficient administrative processes (including dubious practices that could be aimed at trying to minimize applicants' claims) are applied, not complying with international good practices in research evaluation. These effects occur year on year, regardless of the political party in charge.

Regrettably, the particular case study illustrated in this letter surely does not constitute an isolated example. Such practices may occur in other regions of both Spain and other countries, with greater or lesser intensity, thus harming the most vulnerable elements of the research ecosystem, such as young researchers and consolidated groups offering lines of research of interest to the local industry.

It is disheartening to see how regional public governments manage science with such disinterest, inefficiency, and lack of professionalism, while demanding the maximum from researchers. 


\section{Coda: towards the professionalization of research evaluation}

Paradoxically, through this particular case (a regional call for emerging groups), general problems in research evaluation have emerged (e.g., transparency, evaluation delays), beyond "good or bad bibliometrics" (e.g., the use of the h-index or journal impact factor for individual researchers' evaluations, the use of Google Scholar for social sciences and humanities, or the use of altmetrics for alternative impact evidences, to name but a few of the current discussion poles), translating the problem from research evaluation to research management.

Precisely, the origin of the problem comes from not placing research at the center of the country's (regional) social and economic machinery, but as an addendum far from the political center of gravity, thus resulting in a lack of strategic interest in managing science efficiently. The lack of regularization of the professional activity of bibliometrics in particular, and research evaluation in general, only reinforces such mismanagement of science.

Despite the existence of declarations (DORA, 2012) and manifestos (Hicks et al., 2015) with an international scope, treating the evaluation of research, the lack of organizations with a capacity to exert true pressure and "professional jurisdiction" (Jappe; Heinze, 2020) causes these best practices to be diluted in the design of public research policies. Furthermore, the fact that these good practices are not even unanimously accepted by the entire bibliometrics community only aggravates the problem of the lack of scientific authority (low-level auctoritas). This fact undoubtedly causes the low and inconsistent adoption of the DORA Declaration and Leiden Manifesto in research evaluation procedures carried out worldwide by governmental entities, which ultimately finance, manage, and evaluate research (high-level potestas).

It would be desirable for some national and international agencies and associations to be transformed to carry out regulatory functions regarding the professional activity of research evaluation, as an activity whose practice is applied according to knowledge generated by the corresponding scientific community, requiring specific and specialized training. The absence of advanced courses and postgraduate programs in this area might be one of the main causes of the poor evaluation of research-not only in Spain. It should be compulsory for such accredited specialists to be involved in the design of scientific policies that include any type of evaluation process, together with specialists from each area of knowledge.

In the same way that one would not accept being vaccinated by a person other than a nurse, we should not accept that the evaluation of scientific activity be conducted by people without adequate training, especially if we consider the repercussions of research activity, not only for research personnel but for a society that could benefit from scientific findings (the Covid-19 vaccine being just one recent example in the media, among many others that remain unknown to the general public).

In an age where sustainability and transparency are under the media spotlight, it is perhaps time to put these values into practice, especially in the area of scientific research management. To this end, governments should begin to regularize this professional activity, based on the existence of national entities (aligning research evaluation best practices with the social, cultural, and economic conditions of each region, ensuring fair evaluation processes) coordinated by an international nongovernmental entity (channeling the findings of the scientific community and favoring consensus on evaluation), which should ensure and protect the rights and obligations of researchers, practitioners, and all users and clients related to the ecosystem of science and scientific communication assessment worldwide.
Governments must conceive research as the economic engine of their country and a sustainable generator of well-being for their citizens

When such an organization officially regulates the professional activity of research evaluation, it could discuss and implement the specific bibliometric techniques that should be employed in the official practice of the profession when evaluating projects, accreditations, promotions, research periods, etc.

However, for this to occur, governments must conceive research as the economic engine of the country and a sustainable generator of quality of life and well-being for their citizens. Otherwise, scientific activity (and its evaluation) will be an iceberg torn off from the poles and drifting (as it currently is), to later melt and hit the coast in the form of a giant wave.

Yours sincerely,

Dr. Enrique Orduña-Malea

\section{Note}

1. The fields included are the following:

Biosciences and biotechnology; Biomedicine; Agricultural and agrifood sciences; Education, Sport sciences; Mathematics; Social sciences; Materials sciences; Chemistry; Environmental sciences: Philology, Literature, and Art; Law; Economy; Energy and Transport; History and Archaeology; Industrial production; Civil engineering and Engineering for society; Psychology; Information and Communication technologies. 


\section{References}

Aguillo, Isidro F. (2021). "Respuesta a Delgado-López-Cózar et al. Factor de impacto: Muchas declaraciones y pocos resultados. Letter". Profesional de la información, v. 30, n. 3, e300315.

https://doi.org/10.3145/epi.2021.may.15

Codina, Lluís (2021). “Carta: por un cambio en la evaluación de la investigación científica: 'no tirar al niño junto con el agua sucia'. Profesional de la información, v. 30, n. 4, e300418.

https://doi.org/10.3145/epi.2021.jul.18

Delgado-López-Cózar, Emilio; Ràfols, Ismael; Abadal, Ernest (2021). “Letter: A call for a radical change in research evaluation in Spain". Profesional de la información, v. 30, n. 3, e300309.

https://doi.org/10.3145/epi.2021.may.09

DORA. San Francisco Declaration on Research Assessment (2012).

https://sfdora.org/read

Hicks, Diana; Wouters, Paul; Waltman, Ludo; De-Rijcke, Sarah; Ràfols, Ismael (2015). "Bibliometrics: The Leiden Manifesto for research metrics". Nature, n. 520, pp. 429-431.

https://doi.org/10.1038/520429a

Jappe, Arlette; Heinze, Thomas (2020). "Jurisdiction of bibliometrics". In: Ball, Rafael (ed.). Handbook bibliometrics. Berlin: De Gruyter Saur, pp. 91-98. ISBN: 9783110642278

https://doi.org/10.1515/9783110646610-010

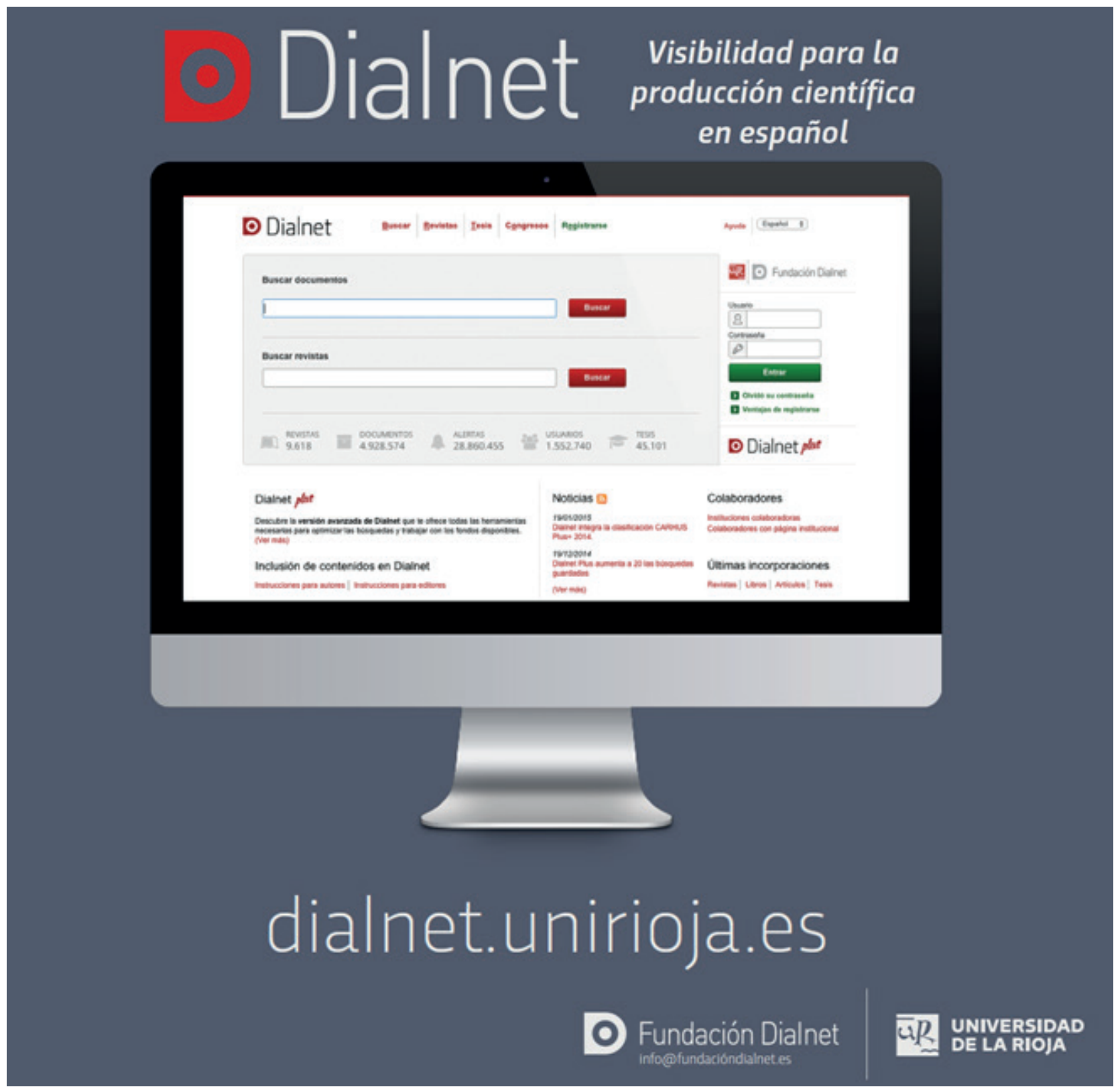

